\title{
Non-atypical endometrial hyperplasia: risk factors for occult endometrial atypia and malignancy in patients managed with hysterectomy
}

\author{
Lee Shi Hui, MBBS ${ }^{1}$, Selina Hui Men Chin, MBBS ${ }^{1}$, Charissa Goh, MBBS ${ }^{1}$, Lin Xiao Hui, MBBS², \\ Manisha Mathur, MBBS, MRCOG, FRCOG ${ }^{1}$, Timothy Lim Yong Kuei, MBBS, MRCOG, FRCOG², \\ Felicia Chin Hui Xian, MBBS, MRCOG, MMed ${ }^{2}$

\footnotetext{
${ }^{1}$ Department of Obstetrics \& Gynecology, ${ }^{2}$ Department of Gynaecological Oncology, KK Women's and Children's Hospital, Singapore
}

\section{Objective}

To determine the risk factors for occult endometrial atypia and malignancy in patients diagnosed with non-atypical endometrial hyperplasia (NEH) on endometrial biopsy.

\section{Methods}

All new cases of NEH diagnosed between April 2015 and March 2016 at KK Women's and Children's Hospital, who underwent hysterectomy as first-line treatment, were included in the study. Patients with a history of endometrial hyperplasia or malignancy were excluded from the study. Patient demographics (e.g., age, parity, body mass index [BMI]), medical history, and clinical presentation were obtained for analysis.

\section{Results}

In total, 262 patients were diagnosed with NEH, of which $18.3 \%(n=48)$ underwent hysterectomy as first-line management. The average time to surgery was $77.0 \pm 35.7$ days. All cases were diagnosed by dilation and curettage, and hysteroscopy. The mean age was 51 years, and the mean BMI was $26.9 \pm 5.8 \mathrm{~kg} / \mathrm{m}^{2}$. Histology from the hysterectomy specimen showed $9(18.8 \%)$ patients with atypical hyperplasia and $2(4.2 \%)$ with grade 1 , stage $1 \mathrm{~A}$ endometrioid adenocarcinoma. Patients with higher grade final pathology had significantly lower median parity (1 vs. $2, P=0.039)$, higher mean BMl ( $30.1 \pm 6.5$ vs. $\left.25.9 \pm 5.3 \mathrm{~kg} / \mathrm{m}^{2}, P=0.033\right)$, and $\mathrm{BMl} \geq 30 \mathrm{~kg} / \mathrm{m}^{2}(54.5 \%$ vs. $13.5 \%$, $P=0.008$, odds ratio 7.68 ), compared to patients whose final histology showed NEH or no residual hyperplasia.

\section{Conclusion}

Occult endometrial atypia and malignancy were found in $18.8 \%$ and $4.2 \%$ of patients with an initial diagnosis of NEH, respectively. High BMI and low parity were identified as significant risk factors for high-grade endometrial lesions in patients with NEH.

Keywords: Endometrial hyperplasia; Endometrial neoplasms; Dilation and curettage

\section{Introduction}

Endometrial hyperplasia (EH) was classified by the World Health Organization in 2014 into two categories based on the presence of cytological atypia [1]. Approximately, 200,000 new cases of EH are diagnosed annually in developed countries [2,3]. EH is of significant clinical importance, given that it is the precursor of endometrial carcinoma [4], the most common gynecological cancer in developed countries [5]. The risk of progression to carcinoma is less than $5 \%$
Received: 2020.09.29. Revised: 2020.12.07. Accepted: 2021.02.21. Corresponding author: Lee Shi Hui, MBBS

Department of Obstetrics \& Gynecology, KK Women's and Children's Hospital, 100 Bukit Timah Road, Singapore 229899, Singapore

E-mail: shihui.lee@mohh.com.sg

https://orcid.org/0000-0001-8369-9336

Articles published in Obstet Gynecol Sci are open-access, distributed under the terms of the Creative Commons Attribution Non-Commercial License (http://creativecommons. org/licenses/by-nc/3.0/) which permits unrestricted non-commercial use, distribution, and reproduction in any medium, provided the original work is properly cited.

Copyright $\odot 2021$ Korean Society of Obstetrics and Gynecology 


\section{Obstetrics \& Gynecology Science}

Lee Shi Hui, et al. Risk of atypia and malignancy in NEH

for non-atypical endometrial hyperplasia (NEH) and up to $30 \%$ in atypical hyperplasia (AH) $[4,6]$.

A diagnosis of EH requires histological analysis of endometrial tissue via endometrial biopsy, which can be obtained from outpatient endometrial sampling or endometrial curettage. A comparison of histology from these methods to the corresponding hysterectomy specimen has found a concordance rate ranging from $60 \%$ to $70 \%$ [7-9] for outpatient endometrial sampling and approximately $70 \%[8,9]$ for dilation and curettage (D\&C).

The first-line treatment for NEH is medical therapy with oral or local intrauterine progestins. Successful regression rates with different forms of progestins vary, with reported regression rates ranging from $69 \%$ to $92 \%$ [10]. Surgery for NEH is generally reserved for patients who have progression or persistence despite medical management or relapse of hyperplasia on follow-up [11]. Some patients undergo surgery as first-line management upon diagnosis of NEH due to contraindications to progestins, other gynecological indications for surgery, or patient preferences.

Patients with an initial diagnosis of NEH may be diagnosed with $\mathrm{AH}$ or endometrial malignancy from their final hysterectomy specimen. The risk of high-grade lesions in patients with NEH has not been well established. The aim of this study was to determine the risk of concurrent atypia and endometrial malignancy in patients with NEH and to establish the risk factors for higher grade final pathology.

\section{Materials and methods}

This retrospective study was conducted at a single tertiary hospital in Singapore. All new cases of NEH diagnosed by histopathological analysis of endometrial biopsy conducted between April 2015 and March 2016 were considered for inclusion. Patients with a history of EH or malignancy were excluded. Only patients who underwent hysterectomy as a first-line treatment were included in the analysis. All preoperative and postoperative histological slides were assessed by gynecology pathologists at our tertiary institution.

Patient demographics (e.g., age, ethnicity, parity, body mass index [BMI], and menopausal status), medical history, and use of tamoxifen were obtained. Their clinical presentation, method of diagnosis of NEH (e.g., outpatient endometrial sampling vs. D\&C with hysteroscopy), ultrasound and hysteroscopic findings, and subtype of NEH (e.g., simple vs. complex) were obtained. We also collected data on the indications and routes of surgery, as well as postoperative complications.

Continuous data were presented as mean \pm standard deviation, or median and data range. The independent samples $t$-test or independent-samples Mann-Whitney $U$ test were used for comparisons of continuous variables between the groups. Categorical data were presented as counts and percentages, and comparisons were performed using the Pearson $\chi^{2}$ test or Fisher's exact test, as appropriate. Simple logistic regression analysis was applied to screen several clinical parameters, including age, menopausal status, parity, BMI, diabetes, use of tamoxifen, and ultrasound or hysteroscopic findings of a thickened endometrium. Statistical significance

Table 1. Demographics and clinical presentation of study group

\begin{tabular}{lc}
\hline & Value \\
\hline Demographics & \\
Age at diagnosis (yr) & $51 \pm 7.3$ \\
Ethnicity & $38(79.2)$ \\
$\quad$ Chinese & $6(12.5)$ \\
Malay & $4(8.3)$ \\
Indian & $2(0-8)$ \\
Gravidity & $2(0-5)$ \\
Parity & $26.9 \pm 5.8$ \\
Body mass index (kg/m²) & \\
Menopausal status & $32(66.7)$ \\
$\quad$ Premenopausal & $16(33.3)$ \\
$\quad$ Postmenopausal & \\
Clinical presentation & $35(72.9)$ \\
Abnormal uterine bleeding or postmenopausal & \\
bleeding & $21(43.8)$ \\
Thickened endometrium & $8(16.7)$ \\
Endometrial/endocervical polyp & $3(6.3)$ \\
Abnormal cervical screening test-Endometrial & \\
cells/Atypical glandular cells of uncertain & \\
significance & \\
Thickeroscopic findings & \\
Endometrial polyp & \\
\hline Normal hysteroscopy & \\
\hline
\end{tabular}

Values are presented as mean \pm standard deviation or number (\%).

a) Four patients had hysteroscopic findings of both thickened endometrium and endometrial polyp. 


\title{
Obstetrics \& Gynecology Science
}

\author{
Vol. 64, No. 3, 2021
}

was set at a two-sided $P$-value of $<0.05$. All statistical analyses were performed using SPSS 19 software (IBM Corp., Armonk, NY, USA).

\section{Results}

A total of 262 patients were diagnosed with non-atypical simple and/or complex hyperplasia over a one-year study period. Of these, 48 patients (18.3\%) underwent hysterectomy as first-line management. All 48 patients were diagnosed by means of a $D \& C$ with hysteroscopy, of which 39 patients (81.3\%) had complex hyperplasia without atypia and the remaining patients had simple hyperplasia without atypia. The mean age at diagnosis was 51 years (range, 38-78 years). In our study population, 38 patients $(79.1 \%)$ were of Chinese ethnicity. The median parity was 2 (range, $0-5$ ) and the mean BMI was $26.9 \pm 5.8 \mathrm{~kg} / \mathrm{m}^{2}$. A total of 35 patients $(72.9 \%)$ presented with abnormal uterine bleeding (AUB) or postmenopausal bleeding. The demographics, clinical presentation, and hysteroscopic findings of our study population are presented in Table 1.

The risk factors for EH among our patients are presented in Table 2. Of note, $50 \%$ of our patients $(n=24)$ had at least one risk factor for $\mathrm{EH}$, with the most common being nulliparity $(n=12,25.0 \%)$ and obesity $(n=11,22.9 \%)$, defined as $B M I \geq 30 \mathrm{~kg} / \mathrm{m}^{2}$. A total of $18.7 \%(n=9)$ of patients had diabetes mellitus, and $6.3 \%(n=3)$ were receiving hormone therapy with tamoxifen for breast cancer treatment. One patient had polycystic ovarian syndrome with associated complications of obesity and diabetes mellitus. One patient underwent laparoscopic salpingo-oophorectomy and D\&C

Table 2. Risk factors for endometrial hyperplasia

\begin{tabular}{lc}
\hline Risk factor & Value $(\mathbf{n}=\mathbf{4 8})$ \\
\hline Nulliparous & $12(25.0)$ \\
Obesity $\left(\mathrm{BMI} \geq 30 \mathrm{~kg} / \mathrm{m}^{2}\right)$ & $11(22.9)$ \\
Diabetes mellitus & $9(18.7)$ \\
Use of tamoxifen & $3(6.3)$ \\
Polycystic ovarian syndrome & $1(2.1)$ \\
Granulosa cell tumor & $1(2.1)$ \\
At least 1 risk factor & $24(50.0)$ \\
\hline
\end{tabular}

Values are presented as number (\%).

BMI, body mass index. with hysteroscopy for a known ovarian cyst and endometrial polyp, revealing complex EH without atypia and an ovarian granulosa cell tumor on histology.

The average time to surgery was $77.0 \pm 35.7$ days, with half of the patients undergoing laparoscopic hysterectomy $(n=24)$ as the mode of surgery. Table 3 shows the mode and indications for surgery. A total of 25 patients (52.1\%) opted for surgical management as they had concurrent indications for surgery, such as fibroids, urogynecological symptoms, contraindication to progestins, or symptomatic AUB despite the use of progestin prior to diagnosis of $\mathrm{EH}$. The mean length of hospital stay was $2.9 \pm 1.2$ days.

Two patients had operative complications. One patient with a history of three previous Caesarean sections underwent abdominal hysterectomy and sustained a $1.5 \mathrm{~cm}$ bladder dome injury due to dense bladder adhesions. The postoperative recovery was uneventful, and the patient was discharged two days later. Another patient with severe pelvic endometriosis, obliteration of the pouch of Douglas, and dense adhesions over the bilateral adnexa underwent a laparoscopic hysterectomy. She was readmitted twelve days post-surgery with abdominal pain and was found to have a urinoma secondary to distal ureteric injury. She was referred to the urology department and underwent drainage and ureteric stenting. The ureteric stent was removed, and she was discharged from the urology follow-up.

Table 3. Mode and indication of surgery

\begin{tabular}{ll}
\hline & Value \\
\hline Mode of surgery & \\
Laparoscopic hysterectomy & $24(50.0)$ \\
Abdominal hysterectomy & $13(27.1)$ \\
Vaginal hysterectomy & $8(16.7)$ \\
Laparoscopic/vaginal converted to & $3(6.3)$ \\
$\quad$ laparotomy & \\
Indication of surgery & $23(47.9)$ \\
Patient's preference & $12(25.0)$ \\
Benign gynecology conditions (fibroids, \\
$\quad$ endometriosis, tubo-ovarian abscess etc) \\
Urogynecological symptoms \\
Contraindication to progestins & $6(12.5)$ \\
Symptomatic AUB despite progestins & $4(8.3)$ \\
Ovarian cancer & $2(4.2)$ \\
\hline
\end{tabular}

Values are presented as number (\%).

AUB, abnormal uterine bleeding. 


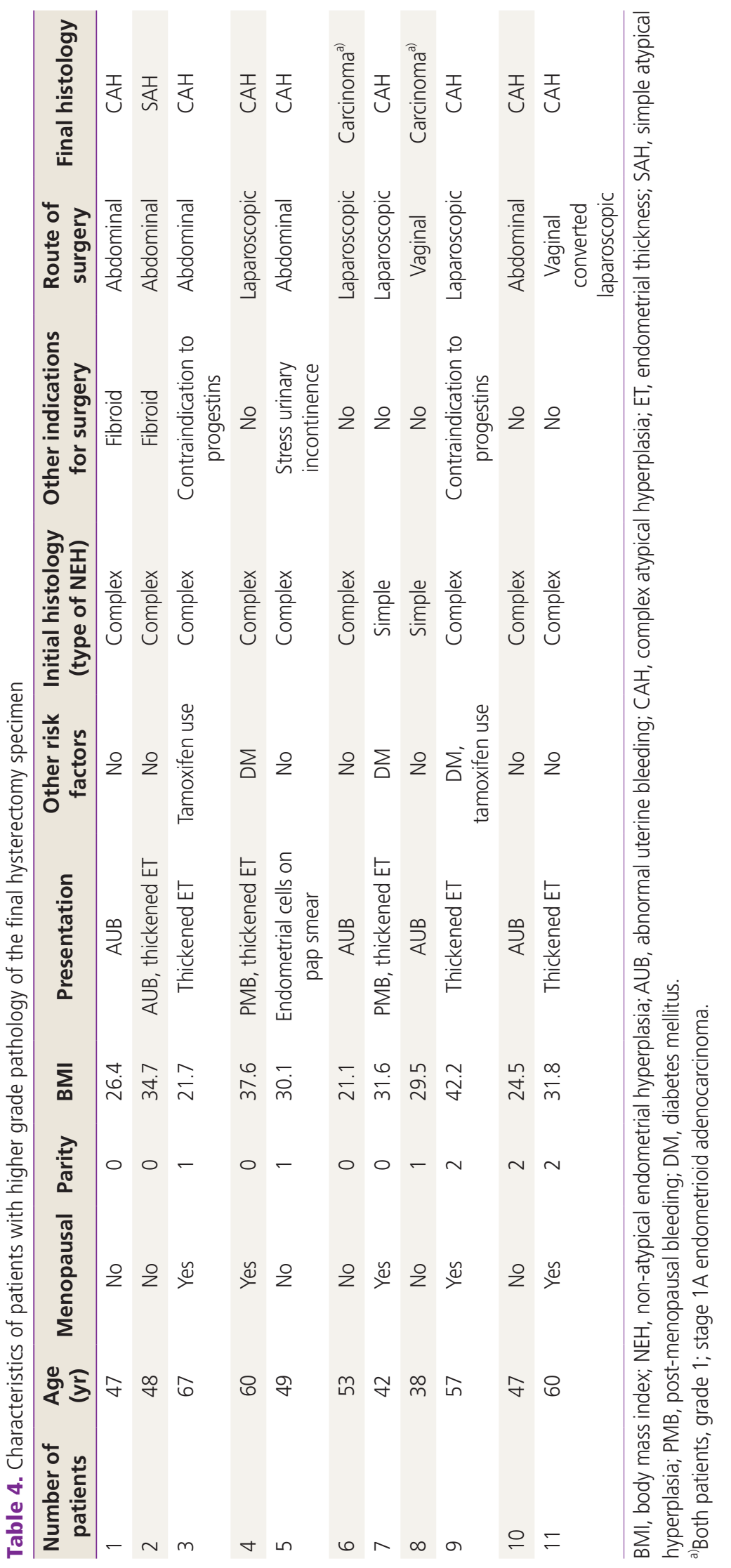




\section{Obstetrics \& Gynecology Science}

Vol. 64, No. 3, 2021

In the final histology of the hysterectomy specimen, 11 of 48 patients (22.9\%) were found to have higher grade pathology, of which 9 patients (18.8\%) were diagnosed with $\mathrm{AH}$ and 2 patients (4.2\%) with endometrial carcinoma. The remaining 20 patients (41.7\%) had NEH, and 17 patients (35.4\%) had no residual hyperplasia. Two patients diagnosed with carcinoma were found to have grade 1 , stage $1 \mathrm{~A}$ endometrioid adenocarcinoma. The characteristics of the 11 patients are shown in Table 4.
The patients with higher grade pathology on final histology ( $\mathrm{AH}$ and endometrial carcinoma) were found to have significantly lower median parity (1 vs. 2, P=0.039) compared to the patients whose final histology showed NEH or no residual hyperplasia (Table 5). Nulliparous patients were found to have a higher likelihood of having higher grade final pathology compared to patients with $\geq 2$ previous pregnancies (41.7\% [5 in 13 cases] vs. $12.0 \%$ [ 3 in 25 cases], $P=0.051$, odds ratio 5.24) (Table 5). Also, patients with higher grade

Table 5. Predictive factors for higher grade final histology

\begin{tabular}{|c|c|c|c|c|c|}
\hline Risk factors & $\begin{array}{l}\text { Higher grade final } \\
\text { histology }(n=11)\end{array}$ & $\begin{array}{l}\text { Low grade final histology } \\
\text { (NEH or no residual } \\
\text { hyperplasia, } n=37 \text { ) }\end{array}$ & Odds ratio & $\begin{array}{l}95 \% \text { confidence } \\
\text { interval }\end{array}$ & $P$-value \\
\hline Age (yr) & $51.6 \pm 8.7$ & $50.7 \pm 6.9$ & & & 0.72 \\
\hline \multicolumn{6}{|l|}{ Menopausal } \\
\hline No & $6(54.5)$ & $26(70.3)$ & 1 & - & - \\
\hline Yes & $5(45.5)$ & $11(29.7)$ & 0.51 & $0.13-2.0$ & 0.34 \\
\hline \multicolumn{6}{|l|}{ Parity } \\
\hline Median & 1 & 2 & - & - & 0.039 \\
\hline 0 & $5(45.5)$ & $7(18.9)$ & 5.24 & $0.99-27.69$ & 0.051 \\
\hline 1 & $3(27.3)$ & $8(21.6)$ & 2.75 & $0.46-16.53$ & 0.269 \\
\hline$\geq 2$ & $3(27.3)$ & $22(59.5)$ & 1 & Reference & - \\
\hline \multicolumn{6}{|l|}{$\mathrm{BMI}\left(\mathrm{kg} / \mathrm{m}^{2}\right)$} \\
\hline Mean & $30.1 \pm 6.5$ & $25.9 \pm 5.3$ & - & - & 0.033 \\
\hline$<30$ & $5(45.5)$ & $32(86.5)$ & 1 & Reference & - \\
\hline$\geq 30$ & $6(54.5)$ & $5(13.5)$ & 7.68 & $1.69-34.96$ & 0.008 \\
\hline \multicolumn{6}{|l|}{ Diabetes mellitus } \\
\hline No & $8(72.7)$ & $31(83.8)$ & 1 & Reference & - \\
\hline Yes & $3(27.3)$ & $6(16.2)$ & 1.94 & $0.40-9.49$ & 0.42 \\
\hline Use of tamoxifen & $2(18.2)$ & $1(2.7)$ & - & - & 0.092 \\
\hline \multicolumn{6}{|l|}{$\begin{array}{l}\text { Clinical presentation and } \\
\text { characteristics }\end{array}$} \\
\hline $\begin{array}{l}\text { Thickened endometrium on } \\
\text { ultrasound }\end{array}$ & $6(54.5)$ & $15(40.5)$ & & & 0.41 \\
\hline $\begin{array}{l}\text { Thickened endometrium on } \\
\text { hysteroscopy }\end{array}$ & $8(72.7)$ & $16(43.2)$ & & & 0.086 \\
\hline $\begin{array}{l}\text { D\&C hysteroscopy done by } \\
\text { trainee }\end{array}$ & $7(63.6)$ & $23(62.2)$ & & & 0.93 \\
\hline $\begin{array}{l}\text { Initial histology with } \\
\text { complex NEH }\end{array}$ & $9(81.8)$ & $30(81.1)$ & & & 0.95 \\
\hline Time to surgery (days) & $87.7 \pm 31.0$ & $73.9 \pm 36.7$ & & & 0.26 \\
\hline $\begin{array}{l}\text { Use of progestin therapy } \\
\text { before surgery }\end{array}$ & $6(54.5)$ & $17(45.9)$ & & & 0.62 \\
\hline
\end{tabular}

Values are presented as mean \pm standard deviation or number (\%).

$\mathrm{NEH}$, non-atypical endometrial hyperplasia; BMI, body mass index; D\&C, dilation and curettage. 


\section{Obstetrics \& Gynecology Science}

Lee Shi Hui, et al. Risk of atypia and malignancy in NEH

final histology had significantly higher mean BMI $(30.1 \pm 6.5$ vs. $\left.25.9 \pm 5.3 \mathrm{~kg} / \mathrm{m}^{2}, P=0.033\right)$. There was a statistically significant difference between the two groups when comparing a BMl of $\geq 30 \mathrm{~kg} / \mathrm{m}^{2}$ (54.5\% [6 in 11 cases] vs. $13.5 \%$ [5 in 37 cases], $P=0.008$, odds ratio 7.68 ).

No significant difference was noted between the two groups for the remaining risk factors, such as age, menopausal status, diabetes, or use of tamoxifen. There was also no significant difference between the two groups for ultrasound or hysteroscopic findings of a thickened endometrium, and among the experience of the surgeon performing the D\&C with hysteroscopy (trainee vs. specialist). The initial histology showing simple vs. complex NEH and time to surgery between the two groups was also not significantly different. Other risk factors, such as polycystic ovarian syndrome and granulosa cell tumors, were not used for statistical comparison, as only one patient was diagnosed with each of these risk factors.

There were 23 patients who received progestin therapy for the management of AUB or for interim treatment of $\mathrm{NEH}$ while awaiting surgery. The type of progestin used included norethisterone, medroxyprogesterone, and megestrol acetate. The dose ranged from 10-30 mg/day for patients given norethisterone and medroxyprogesterone, and 80-160 mg/ day for patients given megestrol acetate. The use of progestin therapy before surgery was not found to be significantly associated with the grade of the final histology (Table 5).

\section{Discussion}

EH is diagnosed via histological analysis of endometrial tissue obtained from outpatient endometrial sampling or endometrial curettage. D\&C has traditionally been considered the gold standard procedure for the investigation of endometrial pathologies. In our study, all patients were diagnosed with NEH using D\&C with hysteroscopy. However, $4.2 \%$ of patients had a final diagnosis of endometrial cancer from hysterectomy specimens. These results are similar to those of previous studies where $1.1 \%$ to $13.7 \%$ of patients initially diagnosed with $\mathrm{NEH}$ were found to have endometrial cancer in the final hysterectomy specimen [12-16]. Our study also found that $18.8 \%$ of patients with an initial diagnosis of $\mathrm{NEH}$ had a final histology of $\mathrm{AH}$ from the hysterectomy specimen. Previous studies have found a wide range of misdiagnoses of atypia between endometrial biopsy and hysterectomy specimens, ranging from $1.1 \%$ to $50 \%[12,17-19]$. The limitation of endometrial curettage is thought to be due to endometrial pathologies in focal lesions, and other authors have recommended that patients with a diagnosis of NEH require close follow-up or further investigations, such as targeted hysteroscopic biopsy of the endometrium in addition to curettage, especially if AUB persists [18,20-22].

In our study, when patients with lower and higher final grade histology were compared, high BMI, especially BMI $\geq 30 \mathrm{~kg} / \mathrm{m}^{2}$, and lower parity were identified as significant risk factors for higher grade final histology (Table 5). Prior studies that identified risk factors for higher grade final histology mostly included both NEH and AH patients. Only one other study included patients with NEH undergoing hysterectomy. Lee et al. [23] found that $12.1 \%$ and $3.2 \%$ of patients with $\mathrm{NEH}$ had occult AEH or endometrial carcinoma in hysterectomy specimens, respectively, and identified age (odds ratio $=1.09, P<0.01$ ) and complex subtype (odds ratio=3.34, $P<0.01)$ as independent risk factors for higher grade final histology. Other studies that included patients with both NEH and $\mathrm{AH}$ at initial diagnosis had similar outcomes to ours. Dolanbay et al. [13] reviewed 82 women with $\mathrm{NEH}$ and $\mathrm{AH}$ diagnosed by endometrial sampling or $\mathrm{D} \& \mathrm{C}$. In this study, $13.7 \%$ of patients with NEH and $66.6 \%$ of patients with $\mathrm{AH}$ had endometrial carcinoma in their final hysterectomy specimen. Similar to our study, it was found that patients with a final histology of endometrial cancer had significantly higher BMI $(28.75 \pm 4.08$ vs. $32.42 \pm 3.4, P<0.05)$. They also identified age, mean weight, and diabetes as factors that were significantly higher in patients with a final diagnosis of endometrial cancer [13]. Kadirogullari et al. [19] reviewed 158 patients diagnosed with NEH or $\mathrm{AH}$ and found that 15 patients had endometrial cancer on final hysterectomy specimen. Two patients were diagnosed with NEH on initial biopsy, and the other 13 patients were diagnosed with $\mathrm{AH}$. Similar to our study, patients with endometrial carcinoma in the final hysterectomy specimen had significantly lower parity ( $3.11 \pm 1.62$ vs. $1.93 \pm 1.79, P<0.05)$. They also found age, postmenopausal status, and endometrial thickness as predictive risk factors for endometrial cancer in the final histology specimen.

The NEH group had a high spontaneous regression rate. Our study found that $35.4 \%$ of the patients had no residual hyperplasia on the final histology. This is similar to previous 


\title{
Obstetrics \& Gynecology Science
}

\author{
Vol. 64, No. 3, 2021
}

studies, with results ranging from $37.4 \%$ to $59.49 \%[12,17]$. Given the high spontaneous regression rate of NEH and high success rate with treatment with progestins, current guidelines by the Royal College of Obstetricians and Gynecologists recommend conservative treatment as first-line management [11]. However, caution must be exercised for patients who are managed conservatively, as in patients with NEH who were found to have complete regression after progestin treatment; long-term follow-up noted a relapse rate ranging from $12.7-41 \%[24,25]$. Gallos et al. [26] found that in patients treated with the levonorgestrel-releasing intrauterine system for complex NEH, $32.6 \%$ of those with a BMI $\geq 35 \mathrm{~kg} /$ $\mathrm{m}^{2}$ experienced relapse compared to only $3.3 \%$ of women with a $\mathrm{BMl}<35 \mathrm{~kg} / \mathrm{m}^{2}(P<0.001)$ over a 9 years study period. Hence, patients managed conservatively need to be aware of the high risk of relapse, especially in those with a high BMI, and this should be considered when formulating a management plan.

Moreover, there remains a risk of progression to $\mathrm{AH}$ and endometrial cancer. Iversen and Dueholm [27] found that, in patients with complex NEH, the 5-year risk of developing endometrial cancer or atypia was $20 \%$. While most of the endometrial cancers were diagnosed in the first year, indicating the possibility of missed diagnosis at the time of baseline sample, they also noted a significant risk of progression to atypia or endometrial cancer of $9 \%$ after one year, and a $30 \%$ risk of hysterectomy within five years. A long-term study of postmenopausal women with NEH had higher rates of progression to type 1 endometrial cancer ( $8.2 \%$ vs. $0.8 \%$, $P<0.0001)$, persistent EH (21.9\% vs. $0.7 \%, P<0.0001)$, future surgical intervention ( $50.7 \%$ vs. $15.4 \%, P<0.0001)$, and future hysterectomy $(34.3 \%$ vs. $9.6 \%, P<0.0001)$, compared to postmenopausal women with atrophic endometrium [28].

\section{Strengths and limitations}

Patients with an initial diagnosis of NEH whose hysterectomy specimen reveals higher-grade pathology are not commonly reviewed. To our knowledge, this is the second study to investigate the risk factors for concurrent atypia and malignancy in patients with NEH. In addition, we present a unique group of patients who were all diagnosed by D\&C with hysteroscopy. All preoperative and postoperative histology slides were assessed by gynecology pathologists in our tertiary institution, where cases with challenging histopathological diagnoses are discussed in the departmental multidisciplinary team to achieve a consensus. However, this study was limited by the small sample size of 48 patients. Our study outcome grouped patients with a final histological diagnosis of lowvs. higher-grade lesions, as subgroup analysis to predict risk factors separately for patients with atypia and endometrial cancer were not significant due to the small sample size.

\section{Conclusion}

The current guidelines recommend conservative therapy for $\mathrm{NEH}$, given its high spontaneous regression rate and high treatment success rate [11], although the optimal duration and frequency for follow-up are yet to be determined. The limitations of curettage must be acknowledged, with $22.9 \%$ of patients in our study with an initial diagnosis of NEH having higher grade final pathologies, including 4.2\% diagnosed with endometrial cancer. Our study identified high BMI and low parity as significant risk factors for the presence of highgrade endometrial lesions in patients with NEH. Larger studies will be useful in confirming these study findings and help guide future clinicians in deciding the optimal management of NEH. In view of the possibility of underdiagnosis in the initial sample, as well as a high risk of relapse and progression to higher grade lesions in patients with risk factors, the diagnosis of NEH should not be taken lightly. Perhaps not all patients with NEH should be managed the same; patients with risk factors may benefit from closer follow-up, with hysterectomy as a management option, especially if conservative management has failed.

\section{Conflict of interest}

No potential conflict of interest relevant to this article was reported.

\section{Ethical approval}

Ethics approval for this study was obtained from the Singhealth Centralized Institution Review Board. The study was performed in accordance with the principles of the Declaration of Helsinki. 


\section{Obstetrics \& Gynecology Science}

Lee Shi Hui, et al. Risk of atypia and malignancy in NEH

\section{Patient consent}

Written informed consent and the use of images from patients are not required for the publication.

\section{Funding information}

None.

\section{References}

1. Emons G, Beckmann MW, Schmidt D, Mallmann P; Uterus commission of the Gynecological Oncology Working Group (AGO). New WHO classification of endometrial hyperplasias. Geburtshilfe Frauenheilkd 2015;75:135-6.

2. Vereide $A B$, Arnes $M$, Strame B, Maltau JM, Ørbo A. Nuclear morphometric changes and therapy monitoring inpatients with endometrial hyperplasia: a study comparing effects of intrauterine levonorgestrel and systemic medroxyprogesterone. Gynecol Oncol 2003;91:526-33.

3. Ozdegirmenci O, Kayikcioglu F, Bozkurt U, Akgul MA, Haberal A. Comparison of the efficacy of three progestins in the treatment of simple endometrial hyperplasia without atypia. Gynecol Obstet Invest 2011;72:10-4.

4. Kurman RJ, Kaminski PF, Norris HJ. The behavior of endometrial hyperplasia. A long-term study of "untreated" hyperplasia in 170 patients. Cancer 1985;56:403-12.

5. Amant F, Mirza MR, Koskas M, Creutzberg CL. Cancer of the corpus uteri. Int J Gynecol Obstet 2018;143(Suppl 2):37-50.

6. Lacey JV Jr, Sherman ME, Rush BB, Ronnett BM, loffe $\mathrm{OB}$, Duggan MA, et al. Absolute risk of endometrial carcinoma during 20-year follow-up among women with endometrial hyperplasia. J Clin Oncol 2010;28:788-92.

7. Ilavarasi CR, Jyothi GS, Alva NK. Study of the efficacy of pipelle biopsy technique to diagnose endometrial diseases in abnormal uterine bleeding. J Midlife Health 2019;10:75-80.

8. Demirkiran F, Yavuz E, Erenel H, Bese T, Arvas M, Sanioglu C. Which is the best technique for endometrial sampling? Aspiration (Pipelle) versus dilatation and curettage (D\&C). Arch Gynecol Obstet 2012;286:1277-82.

9. Gungorduk K, Asicioglu O, Ertas IE, Ozdemir IA, Ulker
MM, Yildirim G, et al. Comparison of the histopathological diagnoses of preoperative dilatation and curettage and Pipelle biopsy. Eur J Gynaecol Oncol 2014;35:53943.

10. Gallos ID, Shehmar M, Thangaratinam S, Papapostolou TK, Coomarasamy A, Gupta JK. Oral progestogens vs levonorgestrel-releasing intrauterine system for endometrial hyperplasia: a systematic review and metaanalysis. Am J Obstet Gynecol 2010;203:547.e1-10.

11. Royal College of Obstetricians \& Gynaecologists. Management of Endometrial Hyperplasia [Internet]. London (UK): Royal College of Obstetricians \& Gynaecologists; c2016 [cited 2021 Jan 31]. Available from: https://www. rcog.org.uk/globalassets/documents/guidelines/greentop-guidelines/gtg_67_endometrial_hyperplasia.pdf.

12. Gundem G, Sendag F, Kazandi M, Akercan F, Mgoyi L, Terek MC, et al. Preoperative and postoperative correlation of histopathological findings in cases of endometrial hyperplasia. Eur J Gynaecol Oncol 2003;24:330-3.

13. Dolanbay M, Kutuk MS, Uludag S, Bulut AN, Ozgun MT, Ozcelik B, et al. Concurrent endometrial carcinoma in hysterectomy specimens in patients with histopathological diagnosis of endometrial hyperplasia in curettage specimens. Ginekol Pol 2015;86:753-8.

14. Çakmak Y, Öge T, Uslu E, Kavak Cömert D, Aydin tosun Ö. Evaluation of concurrent endometrial cancer in patients with endometrial hyperplasia; 10 years experience as a tertiary center. Zeynep Kamil Tıp Bülteni 2019;50:222-6.

15. Chen YL, Wang KL, Chen MY, Yu MH, Wu CH, Ke YM, et al. Risk factor analysis of coexisting endometrial carcinoma in patients with endometrial hyperplasia: a retrospective observational study of Taiwanese Gynecologic Oncology Group. J Gynecol Oncol 2013;24:14-20.

16. Travaglino A, Raffone A, Saccone G, D'Alessandro P, Arduino $B$, de Placido $G$, et al. Significant risk of occult cancer in complex non-atypical endometrial hyperplasia. Arch Gynecol Obstet 2019;300:1147-54.

17. Kleebkaow P, Maneetab S, Somboonporn W, Seejornj K, Thinkhamrop J, Kamwilaisak R. Preoperative and postoperative agreement of histopathological findings in cases of endometrial hyperplasia. Asian Pac J Cancer Prev 2008;9:89-91.

18. Saygili H. Histopathologic correlation of dilatation and currettage and hysterectomy specimens in patients 


\section{Obstetrics \& Gynecology Science}

Vol. 64, No. 3, 2021

with postmenopausal bleeding. Eur J Gynaecol Oncol 2006;27:182-4.

19. Kadirogullari P, Atalay CR, Ozdemir O, Sari ME. Prevalence of co-existing endometrial carcinoma in patients with preoperative diagnosis of endometrial hyperplasia. J Clin Diagn Res 2015;9;QC10-4.

20. Epstein E, Ramirez A, Skoog L, Valentin L. Dilatation and curettage fails to detect most focal lesions in the uterine cavity in women with postmenopausal bleeding. Acta Obstet Gynecol Scand 2001;80:1131-6.

21. Lee DO, Jung MH, Kim HY. Prospective comparison of biopsy results from curettage and hysteroscopy in postmenopausal uterine bleeding. J Obstet Gynaecol Res 2011;37:1423-6.

22. Barut A, Barut F, Arikan I, Harma M, Harma MI, Ozmen Bayar U. Comparison of the histopathological diagnoses of preoperative dilatation and curettage and hysterectomy specimens. J Obstet Gynaecol Res 2012;38:16-22.

23. Lee N, Lee KB, Kim K, Hong JH, Yim GW, Seong SJ, et al. Risk of occult atypical hyperplasia or cancer in women with nonatypical endometrial hyperplasia. J Obstet Gynaecol Res 2020 Sep 17 [Epub]. https://doi.org/10.1111/ jog. 14474.

24. Gallos ID, Krishan P, Shehmar M, Ganesan R, Gupta JK. Relapse of endometrial hyperplasia after conservative treatment: a cohort study with long-term follow-up. Hum Reprod 2013;28:1231-6.

25. Ørbo A, Arnes $M$, Vereide $A B$, Straume B. Relapse risk of endometrial hyperplasia after treatment with the levonorgestrel-impregnated intrauterine system or oral progestogens. BJOG 2016;123:1512-9.

26. Gallos ID, Ganesan R, Gupta JK. Prediction of regression and relapse of endometrial hyperplasia with conservative therapy. Obstet Gynecol 2013;121:1165-71.

27. Iversen ML, Dueholm M. Complex non atypical hyperplasia and the subsequent risk of carcinoma, atypia and hysterectomy during the following 9-14 years. Eur J Obstet Gynecol Reprod Biol 2018;222:171-5.

28. Rotenberg O, Fridman D, Doulaveris G, Renz M, Kaplan J, Gebb J, et al. Long-term outcome of postmenopausal women with non-atypical endometrial hyperplasia on endometrial sampling. Ultrasound Obstet Gynecol 2019;55:546-51. 